UDK: 821.134.2(862).09-31 Ваљехо Ф.

$811.134 .2(862) ' 276.2$

DOI: https://doi.org/10.18485/legado_hispanico.2020.ch18

\author{
Jasmina Marki $\check{c}^{1}$ \\ Universidad de Ljubljana \\ Eslovenia
}

\title{
LA PASIÓN POR EL IDIOMA EN LA RAMBLA PARALELA Y LA VIRGEN DE LOS SICARIOS
}

\begin{abstract}
Resumen
Una de las mayores pasiones de Fernando Vallejo (Medellín, Colombia, 1942), biólogo, escritor, cineasta, aficionado a la música clásica, es la pasión por la lengua en sus más diversas dimensiones. Le fascina la lengua cambiante, en su incesante movimiento, en sus múltiples formas pero critica la actitud normativa de las instituciones académicas y el uso de la lengua para fines políticos. El objetivo de este estudio es mostrar el lugar central que ocupa la lengua en dos novelas de Vallejo: La Virgen de los sicarios y La Rambla paralela y analizar el uso del idioma en los ejemplos seleccionados. En ambas novelas el protagonista es un narrador en primera persona de singular llamado, como el autor, Fernando. En la primera, Fernando es un viejo gramático homosexual que vuelve a su Medellín natal después de haber vivido años fuera del país, en la segunda, el narrador es un viejo escritor homosexual colombiano que llega a Barcelona para dar una conferencia en la Feria del Libro. En la primera prevalecen comentarios sobre el parlache, la jerga de las comunas, mientras que en la segunda los antioqueñismos y colombianismos. El estilo en las novelas analizadas destaca por su complejidad, la superposición de códigos y registros de la lengua hablada y de la escrita, un abundante vocabulario, el uso de metáforas y reiteraciones y la introducción de los más diversos temas. Prevalece la ironía, el sarcasmo, el humor negro, la crítica

\footnotetext{
${ }^{1}$ jasmina.markic@ff.uni-lj.si
} 
punzante de la situación en Colombia en particular y en el mundo en general, pero también una profunda melancolía, una lacerante nostalgia por los tiempos pasados y felices de la infancia.

Palabras clave: Fernando Vallejo, gramática, la jerga de las comunas, antioqueñismos, colombianismos.

¡Qué impredecible es el idioma, cuánto cambian con el tiempo las palabras! $i Q u e$ candidato esté emparentado con cándido, que quiere decir sin malicia ni doblez, puro, inmaculado, limpio, límpido, albo! Lo negro hoy dándoselas de blanco... Las engañosas palabras, las deleznables palabras, las efímeras palabras que llenaron tu vida, capaces de apresar en su fugacidad cambiante toda la pureza y toda la ignominia.

(Vallejo 2011: 8)

\section{Introducción}

Fernando Vallejo (Medellín, Colombia, 1942) en su obra magistral sobre el lenguaje literario Logoi. Una gramática del lenguaje literario, publicada en 1983 y reimprimida varias veces, ofrece una dedicatoria a Cuervo: «A la memoria de Rufino José Cuervo, cuya vida fue la pasión por el idioma». Una de las mayores pasiones de Fernando Vallejo, biólogo, escritor, cineasta, aficionado a la música clásica, es también la pasión por la lengua en sus más diversas dimensiones. A Rufino José Cuervo (Bogotá, 1844 - París, 1911), eminente filólogo colombiano, le ha dedicado un libro, El Cuervo blanco, que es más que una biografía, es un «híbrido entre ensayo y biografía novelada» (Ospina 2015: 249), publicado en 2012. Vallejo venera la genialidad de Cuervo que transformó su Diccionario de construcción y régimen de la lengua castellana en gramática y la gramática en obra de arte. No logró terminarlo porque se le acabó la vida:

El idioma no cabe en un diccionario ni en un manual de gramática porque es escurridizo y burletero, y cuando uno cree que lo tiene en las manos se le fue. ¿Y en un diccionario que fuera a la vez léxico y gramática? ¡Ah, así la cosa cambia! Así la cosa es otra cosa. Cabe porque cabe. Y ése fue el hallazgo de mi paisano, iluminado por Dios (Vallejo 2011: 11). 
En su discurso pronunciado en el centenario de la muerte de Cuervo en Bogotá Vallejo confiesa su amor y su dedicación a la lengua que él mismo usa brillantemente en sus obras. Afirma Vallejo, dirigiéndose a Cuervo en su tumba en el cementerio Père Lachaise de París:

Para ti la patria eran la religión y el idioma. Para mí, la religión del idioma pues otra no he tenido. ¿Pero cuál de tantos, si hay miles? Pues este en que hablo y pienso junto con veintidós países que por sobre la separación de ríos y montañas y selvas y fronteras y hasta la del mar inmenso en cuya otra orilla se encuentra España todavía nos entendemos (Vallejo 2011: 1).

Por otro lado, Vallejo es un acérrimo crítico de la Real Academia Española, de la gramática normativa, que intenta aprisionar la lengua en una camisa de fuerza, fijarla, limpiarla y darle esplendor. Al contrario, la lengua vive, cambia, se metamorfosea: «las palabras cambian de significado. Cambian en su sonido y se van transformando en otras. Ahora con mayor razón porque el cambio va más rápido. Los idiomas van cambiando a una velocidad alucinante» (Villena Garrido 2005). Además, se opone a la gramática como reflejo del poder político y símbolo de la nación, a la postura decimonónica oficial y a los presidentes gramáticos de Colombia. Vallejo sí defiende el buen uso del idioma, como se nota en las dos novelas analizadas, pero considera la lengua en perpetuo cambio. Le interesan las múltiples facetas del castellano y la lengua hablada que introduce en sus novelas: «El lenguaje común me parece muy interesante por sus cambios. El lenguaje literario es como otro idioma» (Villena Garrido 2005). Al lenguaje literario le ha dedicado la obra Logoi que, según él, es el libro que hizo para enseñarse a escribir (Villena Garrido 2005). «El idioma de la literatura difiere en vocabulario y en sintaxis del lenguaje de la calle. Es un idioma que aunque utilice colombianismos o mexicanismos no puede ser local» (Villena Garrido 2005).

\section{La gramática en La Virgen de los sicarios y La Rambla parelala}

En las dos novelas analizadas, el idioma, en su uso y como objeto de reflexión y crítica, ocupa un lugar central. En ambas novelas el protagonista es Fernando, en La Virgen de los sicarios es un viejo gramático homosexual; en La Rambla paralela un viejo escritor homosexual a punto de morir². Todas sus novelas están escritas en primera persona de

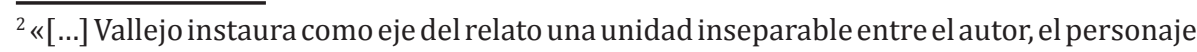
y el narrador, que se concreta haciendo que todos los yo de las novelas compartan no 
singular porque Vallejo considera que el narrador en tercera persona es imposible: «¿Cómo va a saber un pobre hijo de vecino qué piensan los otros si ya no nos aclaramos con este lío que es la mente de uno?» (Villena Garrido 2005).

En La Virgen de los sicarios (publicada en 1994) el narrador se dirige en primera persona a un interlocutor que llama parcero ( $i Y$ "parcerito" qué es? Es aquel a quien uno quiere aunque no se lo diga aunque el bien que lo sabe. Sutilezas de las comunas, pues» (LVS $\left.39^{3}\right)$ ) y le relata sus recorridos por Medellín, su ciudad natal, la de su infancia feliz a la que ha regresado después de muchos años de exilio. La ciudad se ha transformado en un caos por las guerras debidas al narcotráfico, la caótica modernización empujada por la globalización capitalista, la masiva inmigración desde el campo a la capital de Antioquia causando grandes diferencias sociales, miseria y zonas marginadas, caldo de cultivo de la violencia. El narrador o protagonista no pasea solo por la ciudad, sino que va acompañado de dos jóvenes sicarios de los que se enamora, primero de Alexis y luego, tras la muerte de este, de Wílmar, asesino de Alexis. Solo cuando cae asesinado por otros sicarios su segundo amante Wílmar, Fernando se desprende de su yo para transformarse en el hombre invisible que va a la morgue ( “Anfiteatro" llaman aquí a la morgue.» (LVS 116)) a reconocer el cadáver y pasa a la $3^{\text {a }}$ persona de singular (LVS 119-120). Pero, al final de la novela vuelve a la primera persona de singular dirigiéndose al parcero y haciéndole cómplice: «Bueno parcero, aquí nos separamos, hasta aquí me acompaña usted. Muchas gracias por su compañía y tome usted, por su lado, su camino que yo me sigo en cualquiera de estos buses para donde vaya, para donde sea.» (LVS 121). En sus recorridos por la ciudad caótica Fernando reflexiona sobre la lengua, incorpora en su relato la jerga de las comunas ${ }^{4}$, los giros de lengua y expresiones populares de los jóvenes marginales y los giros locales de la zona. Actúa como gramático, comenta y explica los términos que marca entre comillas, pero los va incorporando en su lenguaje ya que se involucra en el mundo de los sicarios. El uso de la

solo el enfado con Colombia y sus gobiernos, la furia anticlerical, la preocupación por la decadencia del lenguaje, el odio a las mujeres, entre muchos otros temas, sino también las señas de identidad del autor: nombre, apellido, edad, sexualidad y nacionalidad» (Lander 2015: 222).

${ }^{3}$ Los ejemplos citados de las novelas llevan entre paréntesis las iniciales del título (LVS, LRP) seguidas del número de la(s) página(s).

${ }^{4}$ El parlache, jerga de los jóvenes de las comunas de Medellín, apareció en los años ochenta del siglo pasado cuando en Medellín reinaba la violencia, el narcotráfico, el sicariato. Actualmente se estudia esta variante del lenguaje que se ha difundido a todos los niveles sociales. 
lengua tanto en La Virgen de los sicarios como en La Rambla paralela está muy ligado al registro oral.

La Rambla paralela, publicada en 2002, es una novela con un específico tratamiento de las voces narradoras que oscilan de modo permanente entre la primera y la tercera persona en un desdoblamiento del narrador que se dirige al que lo escucha (lee). Sus temas recurrentes son el paso del tiempo («Todo lo que algún día es otro día deja de ser» (LRP 189)) y la fugacidad de la vida humana («El aguardiente se lo tomaron, las ilusiones se evaporaron y la vida se fue pasando, pasando, pasando, acabando, acabando, acabando» (LRP 107)), el recuerdo («A veces lo más difícil de recordar es el recordatorio. No hay técnica más incierta que la mnemotecnia. La mnemotecnia es una telaraña colgada del vacío, y la vida un desastre» (LRP 186)), la vejez («La vejez es indigna, indecente, repulsiva, infame, asquerosa, y los viejos no tienen más derecho que el de la muerte» (LVS 88)) y la muerte ( $Y$ Y la Muerte una obsesiva labradora. No descansa» (LVS 56)), temas muy presentes también en la Virgen de los sicarios. Un anciano escritor colombiano es invitado a hablar en la Feria del Libro de Barcelona en la que el país invitado es Colombia. El escritor deambula por Barcelona y bajo la influencia del alcohol y el insomnio se sumerge en sus recuerdos del pasado. Los tiempos del presente, pasado y futuro se funden así como los espacios paralelos por los que se mueve el protagonista (Barcelona, Medellín) que al final morirá en la capital catalana ${ }^{5}$.

Ambas novelas llevan títulos significativos. La Virgen de los sicarios hace referencia al sicariato y a la veneración que le tienen los sicarios a la Virgen Auxiliadora.

Ustedes no necesitan, por supuesto, que les explique qué es una sicario. [...] Abuelo, por si acaso me puedes oír del otro lado de la eternidad, te voy a decir lo que es un sicario: un muchachito, a veces un niño, que mata por encargo (LVS 9).

Medellín es una ciudad católica y muy creyente donde prevalece la religiosidad popular que, insólitamente, se hace componente de la violencia: «Dicen los sociólogos que los sicarios le piden a María Auxiliadora que no les vaya a fallar, que les afine la puntería cuando disparen y que les salga bien el negocio.» (LVS 15-16). Fernando con sus dos amantes entra a rezar en innumerables iglesias de la ciudad. La ciudad de Medellín es también protagonista de la novela, hasta la personificación: «Medellín,

\footnotetext{
${ }^{5}$ Cf. Markič 2019.
} 
también conocido por los alias de Medallo y de Metrallo lo mató.» (LVS 46). En su calidad de gramático el protagonista se pregunta por el género gramatical del nombre de la ciudad: «Sí, señor, Medellín en la noche es bello. ¿O bella? Ya ni sé, nunca he sabido si es hombre o mujer. Lo que sea.» (LVS 31).

En ese desolado y peligroso ambiente de Medellín de finales de los años 80 y los 90 del siglo XX, época en que reinan los carteles del narcotráfico en Colombia, especialmente el de Pablo Escobar en Medellín, cuya presencia se siente en la novela («Mejores pilotos [los gallinazos] nadie, ni los del narcotráfico... Y aterrizan como los pilotos de don Pablo: en un campito insignificante, minúsculo, cual la punta de ese dedo.» (LVS 47)), transcurre el relato de La Virgen de los sicarios. Ese mismo Medellín, tanto el de la infancia como el del presente, aparece en La Rambla paralela, en la memoria de Fernando: la época feliz de su infancia, la vida tranquila de Medellín floreciente (Boston, su barrio natal, Santa Anita, la finca de su infancia, la Sabaneta, los globos que elevaban los niños) y el Medellín actual, peligroso donde reinan el caos total, la violencia y la impunidad, la suciedad, el deterioro.

El título de la La Rambla paralela también es significativo: indica el paralelismo del tiempo y del espacio, de la vida y de la muerte. El narrador se mueve en espacios paralelos: Barcelona, en la que se encuentra como un viejo escritor colombiano a punto de morir y en la que estuvo de joven, el Medellín de su infancia, México y Roma de sus viajes y estancias. También se mueve en tiempos diferentes: el presente de su deambular por las calles de Barcelona; el pasado de sus recuerdos de la infancia en Medellín; el futuro que es ya casi el presente - su muerte-.

Vallejo ataca la hipocresía, critica con humor negro y sarcasmo la situación en Colombia ${ }^{6}$, a los políticos, la Iglesia, las instituciones burocráticas, la humanidad que corre al abismo. La gramática ha sido vinculada al ejercicio del poder político en Colombia desde tiempos coloniales, postura que Vallejo critica con furor como también la lengua hipócrita de los políticos, burócratas y curas: «No hay nada más ruin que la palabra de los políticos o de los curas» (Villena Garrido 2005). El autor ataca con ironía y humor el lenguaje rebuscado, la aparente solemnidad de la burocracia colombiana:

\footnotetext{
${ }^{6}$ «Bueno. La situación en Colombia era así: la industria arruinada, el campo arruinado, la banca arruinada, la clase política desprestigiada, la Iglesia desprestigiada, las Fuerzas Armadas desprestigiadas. La construcción y el comercio como la justicia: paralizados. Y la venalidad, la violencia, la frustración por dondequiera, el desencanto.» (LRP 76).
} 
Del presunto asesino no quedó sino el «presunto» flotando sutilmente en el aire de la Avenida San Juan, hasta que en el smog de los carros la presuntez se esfumó. 0 la presunción, si prefieren y les da por la corrección del idioma en este que fuera el país de gramáticos, siglos ha. De los ladrones, amigo, es el reino de este mundo y más allá no hay otro. Siguen polvo y gusanos. Así que a robar, y mejor en el gobierno que es más seguro y el cielo es para los pendejos (LVS 20).

Fernando se burla de la ignorancia de los presidentes ${ }^{7}$ :

Muchos iban por las Ramblas con sus sandalias, que dejaban ver los pies: «los pieses», como diría nuestro cultísimo ex presidente Miguel de la Madrid Hurtado (LRP 167).

Cuestión pues de semántica, como diría nuestro presidente Barco, el inteligente, que nos gobernó cuatro años con el mal de Alzheimer y le declaró la guerra al narcotráfico y en plena guerra se le olvidó (LVS 42).

El espíritu de Rufino José Cuervo, que Vallejo considera una persona ejemplar, un maestro que dedicó su vida a la lengua sin sucumbir a la política, está presente en las dos novelas tratadas en este estudio.

-Este idioma que algún día fue un idioma hoy es una colcha de retazos -pontificó-. ¿Qué diría Cuervo si estuviera aquí?

¿Qué iba a decir, si Cuervo murió hace cien años! Un muerto con cien años de pudrimiento no tiene ni idea de lo que es hoy la realidad. Esto ha cambiado mucho. Ah, pero eso sí, las que sí no habían cambiado eran las faltas, los atropellos al idioma que Cuervo censuró y que ahí seguían tan campantes como un gallo montado en su gallina (LRP 41).

El café era de lo poco bueno que seguía produciendo Colombia, toda vez que se le murieron sus gramáticos. Tras la muerte de Cuervo fue el acabose (LRP 44).

Y a todas estas preguntará usted: ¿quién fue Cuervo? Hombre, Cuervo (don Rufino José) fue el más grande gramático de Colombia (LRP 45).

Hace ciento cincuenta años en sus «Apuntaciones Críticas al Lenguaje Bogotano» don Rufino José Cuervo indicó que no se dijera «méndigo» sino

\footnotetext{
${ }^{7}$ Miguel de la Madrid Hurtado fue presidente de México desde el 1/12/1982 hasta el 30/11/1988. Virgilio Barco Vargas fue presidente de Colombia en el periodo 1986-1990.
} 
«mendigo», sin tilde y con el acento en la «i». [...] Cuervo se pasó la vida luchando contra molinos de viento (LRP 187).

«El pelao debió de entregarle las llaves a la pinta esa», comentó Alexis, mi niño, cuando le comenté lo sucedido. 0 mejor dicho no comentó: diagnosticó, como un conocedor, al que hay que creerle. Y yo me quedé enredado en su frase soñando, divagando, pensando en don Rufino José Cuervo y lo mucho de agua que desde entonces había arrastrado el río. Con el «pelao» mi niño significaba el muchacho; con «la pinta esa» el atracador; y con «debió de» significaba «debió» a secas: tenía que entregarle las llaves. Más de cien años hace que mi viejo amigo Rufino José Cuervo, el gramático, a quien frecuenté en mi juventud, hizo ver que una cosa es «debe» y otra «debe de». Lo uno es obligación, lo otro duda (LVS 20).

Vallejo juega con el ritmo de la lectura y de la escritura utilizando reiteraciones («y la vida se fue pasando, pasando, pasando, acabando, acabando, acabando.» (LRP 107)), interjecciones y onomatopeyas («-¡Uy maestro, hoy sí se ve usted muy demacrado!» (LRP 75); «-¡Uuuu!silbaba la sirena del barco.» (LRP 122)). Juega con los verbos, los adverbios y los gerundios. Además, con la voz del narrador hace permanentes comentarios sobre el idioma. En sus novelas se incorporan elementos sintácticos, gramaticales y diferentes léxicos específicos. En los diálogos y monólogos aparecen elementos típicos de Colombia en general y, en particular, de Antioquia, del habla local, de su jerga. En La Virgen de los sicarios Fernando presenta un tratado sobre las comunas y la lengua que se usa en esos barrios marginados, empinados sobre las colinas que rodean la ciudad.

Las comunas cuando yo nací ni existían. Ni siquiera en mi juventud, cuando me fui. Las encontré a mi regreso en plena matazón, florecidas, pesando sobre la ciudad como su desgracia. Barrios y barrios de casuchas amontonadas unas sobre otras en las laderas de las montañas, atronándose con su música, envenenándose con el amor al prójimo, compitiendo con las ansias de matar con la furia reproductora. Ganas con ganas a ver cuál puede más. En el momento en que escribo el conflicto aún no se resuelve: siguen matando y naciendo. A los doce años un niño de las comunas es como quien dice un viejo: le queda tan poquito de vida... ya habrá matado a alguno y lo van a matar (LVS 28-29).

El viejo gramático explica a su 'parcero', es decir, a su interlocutor las palabras provenientes de la jerga de las comunas de Medellín: «¿Es 
que estos cerdos del gobierno no son capaces de asfaltar una carretera tan esencial, que corta por en medio mi vida? ¡Gonorreas! (Gonorrea es el insulto máximo en las barriadas de las comunas).» (LVS 10)

En La Rambla paralela el protagonista también hace referencia a las comunas:

Las comunas, los sangrientos barrios de invasión encaramados en las laderas de las montañas de esa ciudad maldita donde vive y reina la que sirve, la Muerte, doña Muerte, misiá Muerte, la panacea universal, la gran justiciera de Colombia que mantiene a raya la impunidad (LRP 136).

Los ejemplos siguientes muestran cómo el protagonista aclara, comenta, reflexiona sobre los términos de la jerga de las comunas, como fierro, muñeco, gonorrea, changón, quebrar, culebra, tombo, balín...

No habla español, habla en argot o jerga. En la jerga de las comunas o argot comunitario que está formado en esencia de un viejo fondo de idioma local de Antioquia, que fue el que hablé yo cuando vivo (Cristo el arameo), más alguna que otra supervivencia del malevo antiguo del barrio de Guayaquil, ya demolido, que hablaron los cuchilleros, ya muertos; y en fin, de una serie de vocablos y giros nuevos, feos, para designar ciertos conceptos viejos: matar, morir, el muerto, el revólver, la policía...Un ejemplo:«¿Entonces qué, parce, vientos o maletas?» «¿Qué dijo? Dijo: "Hola hijo de puta"». Es un saludo de rufianes (LVS 23).

«[...] Déjame que la próxima vez saco el fierro». El fierro es el revólver. Yo al principio creía que era un cuchillo pero no, es un revólver. Ah, y transcribí mal las amadas palabras de mi niño. No dijo «Yo te lo mato», dijo «Yo te lo quiebro». Ellos no conjugan el verbo matar: practican sus sinónimos. La infinidad de sinónimos que tienen para decirlo: más que los árabes para el camello (LVS 25).

[...] le habían dado un día «una mano de changón» en su barrio. Qué es un changón preguntarán los que no saben como pregunté yo que no sabía. Era una escopeta a la que le recortaban el tubo, explicó mi niño. «¿Y para qué se lo cortan?» Que para que la lluvia de balines saliera más abierta y le diera al que estuviera cerca. ¿Y los balines qué? ¿Eran como municiones? Sí, sí eran (LVS 25).

« ¡Corran! ¡Corran! ¡Vengan a ver el muñeco!» El «muñeco» por si usted no lo sabe, por si no los conoce, es el muerto. El vivo de hace un instante pero que ya no (LVS 27). 
Lo matamos por chichipato, por bazofia, por basura, por existir. Porque contaminaba el aire y el agua del río. Ah, «chichipato» quiere decir en las comunas delincuente de poca monta, raticas, eso (LVS 28).

De los muertos de Alexis, cinco fueron gratis, por culebras propias; y cinco pagados, por culebras ajenas. ¿Qué son «culebras»? Son cuentas pendientes. Como usted comprenderá, en ausencia de la ley que se pasa todo el tiempo renovándose, Colombia es un serpentario (LVS 35).

«Ese tombo está enamorado de mí». Un «tombo» es un policía, ¿pero enamorado? ¿Es que es un marica? No, es que lo quiere matar. [...] Cualquier sociólogo chambón de esos que andan por ahí analizando en las «conserjerías para la paz», concluiría de esto que al desquiciamiento de una sociedad le sigue el del idioma. ¡Qué va! Es que el idioma es así, de por sí ya es loco (LVS 56).

En La Rambla paralela el protagonista Fernando y su interlocutor muestran un sentido muy fuerte por el idioma y explican numerosos colombianismos («[...] volvió a oír hablar colombiano y su alma se le inundó de dicha.» (LRP 40)), antioqueñismos, mexicanismos y americanismos en general, a menudo comparándolos al español peninsular y muchas veces refiriéndose a momentos de la historia colombiana, a elementos de su tradición social y cultural, frecuentemente con fuerte crítica y humor sarcástico, al igual que en La Virgen de los sicarios.

Gallinazos (para usted que es de un país civilizado y no sabe) son los buitres, el viejo vultur latino: los que iban de pasajeros sobre los decapitados del río despanzurrándolos: sacándoles, como un niño travieso la cuerda a un reloj, de la panza las tripas (LRP 23).

- ¿Cómo se llama esta avenida? -le preguntó.

- La Rambla Paralela -le contestó.

Pero no iba paralela, corría sesgada. Por esta avenida sesgada llegaron a la pensión, un apartamento oscuro con un pasillo largo. Un «piso» como les dicen en España (LRP 51).

El viejo escribía en español pero se hablaba en antioqueño. A mí con lo experto que soy en leer pensamientos, les confieso que a veces me costaba entenderlo.

-Pensá en cristiano, güevón -le decía remedándolo (LRP 54).

Un «coche» o carro le pasó zumbando (LRP 80). 
-iQué hijueputas tan lambiscones! Lamiéndoles el culo a los muertos como si siguieran vivos. «Vaca vieja no olvida el portillo» decía la abuela.

Lambiscones, que es mexicanismo, significa «lambones», que es colombianismo: aduladores, rastreros, de esos que sobran en el gran velorio de esta vida (LRP 112-113).

- ¿Cómo amanecieron, paisanos, muy enguayabaditos, o qué? -saludó al llegar.

«Enguayabados» es en Colombia, «crudos» en México, en Guatemala «con goma» y en España «con resaca». Y así y así. Una denominación en cada paisito de esta colcha de retazos llamada idioma para el consabido mal del remordimiento tembloroso que nos acomete hoy en la mañana y no nos deja volver a agarrar la copa de la noche (LRP 129).

-Estoy norteado -dijo, como dicen en México, queriendo significar perdido (LRP 153).

«Pendejo» en México es una palabra vulgar pero en Colombia no tiene peso semántico, quiere decir bobito (LRP 157).

En las dos novelas se repiten referencias lingüísticas, como en el caso del término tinto.

Ah, y eso de «Le provoca un tintico» se traduce así en cristiano: «¿Se le antoja un café?» (LRP 41).

Al yo pagar en la recepción nos ofrecieron un café. Un "tinto" como dicen en este país absurdo (LVS 115).

Vallejo introduce en el texto narrado, en boca de su protagonista homónimo, reflexiones sobre la gramática, la fonética, la semántica hasta pequeños tratados etimológicos (p.ej. «Gallinazos (para usted que es de un país civilizado y no sabe) son los buitres, el viejo vultur latino [...]» (LRP 23)). Le preocupan los adverbios terminados en mente:

«Tac... tac... tac...» iba diciendo el reloj incierto del corazón, de tumbo en tumbo, fatigadamente. ¿Fatigadamente? Pensé en los largos adverbios en «mente» del español, tan torpes, tan tontos, tan sosos, y en ese instante supe cómo me iba a morir: como Oudin, resolviendo un problemita pendejo de gramática. ¡Vaya muerte! Y en un hotelito de quinta de Barcelona... Si por lo menos hubiera sido en mi apartamento de México, pero no: por no ponerle punto final a este negocio a tiempo no me fue dado escoger el sitio ni el momento. Y ahora me moría como cualquier mortal, aferrado a 
la vida, miserablemente: con un largo y miserable adverbio en «mente» (LRP 11).

Ahora, pasado el tiempo, me río de esos adverbios en «mente», tan largos pero tan desinflados. Son meras apariencias (LVS 49-50).

Fernando comenta el cambio de significado de algunas palabras como poeta, maestro o hijoeputa:

- ¿Le provoca un tintico, maestro? -oyó que la muchacha le ofrecía a uno de los presentes.

- ¡Ah, caray! -se dijo el viejo- ¿También a este le dicen maestro? Otra palabra que se jodió.

Pero no. Maestros en realidad, aparte de los albañiles y los zapateros, no es que hubiera muchos en Colombia [...] (LRP 40).

La que sí se había jodido por completo era la palabra «poeta», que quedó valiendo en su opinión como «hijoeputa», pues había tantos de los unos como de los otros: no menos de cinco millones. Así pues, decirle hoy a alguien en Colombia «¿Le provoca un tintico, poeta?» era según él como decirle «¿Le provoca un tintico, hijoeputa?» (LRP 41).

En Colombia, de tantos que había y de devaluarse tanto, «hijueputa» quedó valiendo nada. Ayer un insulto, hoy significaba simplemente persona, tipo, un tal, un cual, un fulano, usted, su papá, su tío, yo, el Padre, el Hijo, el Espíritu Santo, alguien y nadie, mucho y poco, todo y nada (LRP 97).

Se enfurece al comprobar que los colombianos se olvidan del verbo oír y lo reemplazan por escuchar:

Que oír hubiera desaparecido de la lengua castellana... ¡De no poderlo creer! La muerte de ese verbo amado le pesaba como una lápida. Era el preludio del fin del mundo.

-El que no oye no escucha. ¡Van rumbo al abismo, locos, sordos! (LRP 156).

Prendió la casetera que mantenía al alcance de la mano en la cabeza y se puso a oír a Gluck. Y oigan bien lo que digo, hijos de puta que están acabando con este idioma: a oír, no a escuchar. A oír, a oír, a oír, a oír, a oír a Gluck, el músico de la muerte. El verbo «escuchar» para él no existía, lo había borrado del diccionario (LRP 186).

Fernando comenta e ironiza sobre aspectos fonéticos («Cuando remedó a algunos en español el viejo descubrió, por un desliz en el tonito, 
que era argentino.» (LRP 73)), compara el uso del español de América y el de España con juegos de palabras («Pasaba del súmum al mínimum, de la cima a la sima» (LRP 78)) criticando a los colombianos que por pedantes se apropian de la pronunciación española peninsular:

Los colombianos de Barcelona hablaban todos con la zeta, como españoles. No acababan ni de llegar a lavar inodoros, e ipso facto estaban hispanizados. Los que llegan a Madrid en cambio no: siguen colombianizados. ¿Por qué? Fenómenos del lenguaje que el viejo no entendía (LRP 33).

Le contaron que un colombiano tenía la mejor librería de la ciudad, y sí, era cierto, según constató el día que fue a verlo: hablaba con la zeta y estaba absolutamente apeninsulado, españolizado. Y eso que era de Envigado, un pueblo de las afueras de Medellín, que es la capital de Antioquia, y que los de allí no cambian: como nacen se mueren, con el mismo tonito y las mismas mañas.

- ¿Oí bien? -se preguntaba el viejo, incrédulo, cuando oía a su paisano pronunciar la zeta.

Era como si a una liebre le hubiera salido lana de oveja. ¡Un milagro! (LRP 33-34).

¿Y esos plurales de segunda persona, «habéis», «entráis», «sacáis», «zumbáis»? ¿Oí bien? ¿Un antioqueño hablando con el vosotros? ¿habráse visto mayor fenómeno?

- ¿Se te contagió España, o qué, pendejo? Dejá de arriar mulas y de hablar como gachupín loco y andate otra vez para la calle que aquí no tenés nada que hacer (LRP 50).

Con cinco días en la península y ya hablaba de «vosotros» y decía «hideputas» como Cervantes (LRP 74).

$[\ldots]$ ¿Me aconseja pegarme un tiro en la cabeza?

-En la cabeza no: en el corazón, preservando la computadora.

-0 sea el ordenador, como decimos en España. En América hablan muy raro, mueven muy raro los labios (LRP 154).

Una de las características del dialecto antioqueño en cuanto a las formas de tratamiento es el voseo («Le hablaba de "vos" como antioqueño por seguirle la corriente. Pero yo antioqueño no soy, Dios libre y guarde.» (LRP 63)), forma de tratamiento familiar que alterna con el tuteo ${ }^{8}$. El voseo puede afectar tanto a las formas verbales (el uso de las formas

\footnotetext{
${ }^{8} C f$. Markič 2017.
} 
verbales de la $2^{a}$ persona de plural más o menos modificadas) como a las pronominales (el uso de vos como sujeto, vocativo, término de preposición; en los demás casos se usan las formas del tuteo). También usted ( $3^{\text {a }}$ p. sg.) se puede usar como forma de tratamiento familiar en alternancia con tú (ejemplo LVS 10) o con vos.

-No te quejés, que maestro no le han dicho jamás en ese país a ningún bellaco de presidente. Además, ¿el dinero no dizque no te importa? ¿Qué más querés? No te dan más porque no tienen más, contentate con eso (LRP 25).

Meses hacía que no lo veía, y lo noté muy recuperado, muy «repuesto». «Ábranse - nos dijo-, que los van a cascar». «Carambas, si alguna sospecha tengo yo a estas alturas del partido, parcero, es que soy más incascable que vos -le contesté-. Pero gracias por la advertencia» (LVS 43).

«Aquí te regalo esta belleza -me dijo José Antonio cuando me presentó a Alexis-que ya lleva como diez muertos». [...] Después le dijo al muchacho: «Vaya lleve a este a conocer el cuarto de las mariposas» (LVS 10).

El tuteo plural (la segunda persona de plural: vosotros) no existe en el español de América, tampoco es de uso en Colombia, en su lugar se usa la forma plural en $3^{\mathrm{a}}$ persona ustedes, forma de tratamiento tanto familiar como formal. Existe la forma reverencial de vos con las formas verbales de la segunda persona de plural y el posesivo vuestro. Se trata de un tono reverencial elevado como, por ejemplo, cuando los sicarios le rezan a la Virgen:

«Madre Santísima, María Auxiliadora, señora de bondad y de misericordia, posternado a vuestros pies y avergonzado de mis culpas, lleno de confianza en vos os suplico atendáis a este ruego: que cuando llegue mi última hora, por fin acudáis en mi socorro para que tenga la muerte del justo. Ahuyentad el espíritu maligno y su silbo traicionero, y libradme de la condenación eterna, que la pesadilla del infierno ya la he vivido en esta vida y con creces: con mi prójimo. Amén» (LVS 52).

En las novelas analizadas aparecen además otras formas del habla antioqueña, como algunas formas típicas de los verbos (semos por somos, haiga por haya) y otros ejemplos morfosintácticos, como el frecuente uso de dizque, expresión proveniente de la amalgama de diz, forma antigua apocopada de la $3^{\text {a }}$ persona del singular de presente de indicativo del verbo decir, y la conjunción que. Se usa como adverbio con valor de 
modalidad evidencial ${ }^{9}$ con el sentido de supuestamente, presuntamente, al parecer y, en el estilo vallejiano, con un matiz irónico y burlón.

-Tenés razón, los viejos semos muy escasos.

Decía «semos» por joder, porburlarse delos campesinos viejosde Antioquia, a los que se pasaba todo el tiempo en su interior «arremedándolos» (LRP 49).

En Colombia eso no falla, ¿por qué ha de fallar aquí? Si en todas partes semos la misma especie bípeda...

¡Y dele con el «semos» y con el bipedalismo prodigioso en que culminó la evolución! (LRP 77).

-La vida es muy corta o muy larga -sentenció-. Por eso, paisanos, acabémonos de tomar lo que haiga (LRP 137).

A ver, ustedes que dizque son tan buenos católicos ime sabrán decir en qué iglesia de Medellín está San Pedro Claver? [...] ¿Y saben, por lo menos, en cuál está San Cayetano? Pues sepan por si no lo saben que en la de San Cayetano [...] (LVS 53).

Que la feria iba siendo un desastre, que dizque porque era la primera a la orilla del mar. Y que dizque porque el público dizque estaba acostumbrado dizque a la del Paseo de Gracia donde dizque en un solo día los libreros vendían más que en los restantes trescientos sesenta y cuatro días del año. Que ese dichoso día todo el mundo compraba libros para regalar (LRP 85).

En las novelas abundan los diminutivos típicos del uso colombiano que señalan frecuentemente un tono irónico, a veces sarcástico del estilo vallejiano Pueden ser tanto positivos como negativos:

Virgencita niña de Sabaneta, que vuelva a ser el que fui de niño, uno solo. Ayúdame a juntar las tablas del naufragio (LVS 31).

[...] uno de esos muchachitos linditos, riquitos, hijos de papá que me fascinan (también) (LVS 19).

En los dos ejemplos siguientes el diminutivo refleja el odio por los políticos de Colombia que según Fernando Vallejo echaron a perder el país:

\footnotetext{
${ }^{9}$ Cf. Pihler Ciglič 2017.
} 
La mariquita de Gaviria borró de un plumazo la palabra «honorabilidad» del diccionario de Colombia. Le siguieron al bellaco Sampedrito y Pastranitas, otros dos (LRP 71). ${ }^{10}$

Con las continuas masacres y el consiguiente cambio en la composición del electorado, Colombia ya estaba madurita (LRP 90).

En el texto de estas dos novelas se intercalan también palabras extranjeras, sobre todo del latín (hasta con comentarios gramaticales), del inglés, del italiano, del francés...

¿A quién preguntarle si ya nadie sabía latín? ¡Pues a un muerto! Que los muertos les pregunten a sus muertos. El latín como lengua muerta que es, se le hacía muy bien para los epitafios. [...] Se está pudriendo en vida el español, no se va a podrir el latín que está muerto! Dejémonos de güevonadas (LRP 54).

He de ir con Colombia a buscarlo para poner en la fachada una placa: «Hic mortus ubique notus». De «moriturus est» pasó a «mortus»: del futuro de la voz pasiva al participio pasado. Se salió con la suya el viejo, todo era cuestión de gramática (LRP 128-129).

Y ahí mismo me quiero morir para redondiar el epitafio, que en mayúsculas latinas ha de decir así, en aposición de mi nombre y a este lado de la puerta: «Vir clarisimus, grammaticus conspicuus, philologus illustrisimus, quoque pius, placatus, politus, plagosus, fraternus, placidus, unum et idem e pluribus unum, summum jus, hic natus atque mortuus est. Anno Domini tal...» (LVS 104).

Y que vamos en la dirección correcta: «in the right direction», como oyó decir en inglés (LVS 34).

En Italia a los periodistas los llaman «i paparazzi», o sea los papagayos; estos de aquí son buitres (LVS 44).

Que tienen el cincuenta por ciento de probabilidades, fifty fifty, de que sus hijos les salgan como ellos, midiendo uno veinte (LVS 103).

«Divinités du Styx, ministres de la mort! Je n'invoquerai point votre pitié cruelle...» (LRP 20).

\footnotetext{
${ }^{10}$ César Augusto Gaviria fue presidente de Colombia entre 1990 y 1994. Ernesto Samper Pizano fue presidente de Colombia entre 1994 y 1998. Andrés Pastrana fue presidente de Colombia entre 1998 y 2002.
} 


\section{Conclusión}

Las reflexiones sobre la lengua de los dos protagonistas, un viejo gramático y un viejo escritor -ambos llevan el nombre del autor: Fernando-son esenciales en la obra de Vallejo tal como lo corroboran los ejemplos presentados. En las novelas analizadas se siente la presencia del admirado filólogo Rufino José Cuervo que

[...] intentó en nuestro idioma la más ambiciosa gramática de cualquier idioma: un diccionario: el Diccionario de construcción y régimen de la lengua castellana, que pretendía describir todos los usos y relaciones, en todas la épocas, de las palabras españolas. A fines del siglo pasado, de su siglo de taxonomías, el filólogo colombiano entrevió la más penosa verdad para un gramático: que el lenguaje humano con su móvil ambigüedad escapa a todo sistema; que la única forma de apresarlo es la más humilde, la enumeración exhaustiva de los diccionarios (Vallejo 2013: 530).

La prosa de Vallejo fluye como un río, «se desboca, desborda, derrapa, desbarranca y se desespera» (Musitano 2012). El estilo en las novelas analizadas destaca por su complejidad, la superposición de códigos y registros de la lengua hablada y de la escrita, un abundante vocabulario, el uso de metáforas y reiteraciones, la intercalación de dichos y proverbios, la introducción de los más diversos temas, las alusiones a escritores, poetas, filósofos, el desdoblamiento del yo del protagonista y su visión del paso del tiempo. Prevalece la ironía, el sarcasmo, el humor negro, la crítica punzante de la situación en Colombia en particular y en el mundo en general, pero también una profunda melancolía, una lacerante nostalgia por los tiempos pasados y felices de la infancia.

La lengua va y viene, cambia, según los caprichos del viento y la altura de las montañas [...]. El idioma no es una roca inconmovible, es terrón que se desmorona, arenisca que se lleva el viento (LRP 157-158).

\section{REFERENCIAS BIBLIOGRÁFICAS}

Astutti 2003: Adriana Astutti. «Odiar la patria y aborrecer la madre: Fernando Vallejo». Boletín 11. Centro de Estudios y Crítica Literaria 11: 107-119. [www.bazaramericano.com] Web. 03/12/2019. Lander 2015: María Fernanda Lander. «El arte de la biografía de Fernando Vallejo». Cuadernos de literatura, XIX, 37: 219-232. 
Markič 2017: Jasmina Markič. «Voseo, tuteo in ustedeo v kolumbijski različici španščine». Ars \& Humanitas, 11/2: 56-72.

Markič 2019: Jasmina Markič. «Traduciendo a Fernando Vallejo: La rambla paralela y Vzporedna ulica». Pejović, Anđelka et al. (Eds.), Estudios hispánicos serbios y retos de la contemporaneidad. Actas de la Segunda Conferencia Nacional de Hispanistas Serbios, Belgrado: Filološki fakultet Univerziteta u Beogradu, 371-386.

Musitano 2012: Julia Musitano. «Detrás de una máscara fantasmagórica: Una lectura de La rambla paralela de Fernando Vallejo». Orbis Tertius, 17, No. 18.

[http://www.orbistertius.unlp.edu.ar] Web. 03/12/2019.

Musitano 2014: Julia Musitano. «Peroratas de un hombre excepcional. Una imagen de sí por Fernando Vallejo». CELEHIS - Revista del Centro de Letras Hispanoamericanas, 23, No. 28: 49-62.

Ospina 2015: María Ospina. «Los embelecos de la gramática: lengua, literatura y herejías gramaticales en la obra de Fernando Vallejo». Cuadernos de Literatura, XIX, 37: 247-273.

Pihler Ciglič 2017: Barbara Pihler Ciglič. «Evidencialna branja prislova dizque $\mathrm{V}$ nekaterih različicah ameriške španščine in njegove ustreznice v slovenščini». Ars \& Humanitas, 11/2: 85-103.

Torres 2010: Antonio Torres. «Lenguaje y violencia en la Virgen de los sicarios, de Fernando Vallejo». Estudis Romànics, 32: 331-338.

Vallejo 2002: Fernando Vallejo. La Rambla paralela. Madrid: Alfaguara.

Vallejo 2006: Fernando Vallejo. La Virgen de los sicarios. Bogotá: Alfaguara. Vallejo 2011: Fernando Vallejo. En el centenario de la muerte de Rufino José Cuervo. Discurso pronunciado en la inauguración del "II Festival de la Palabra" del Instituto Caro y Cuervo, Biblioteca Luis Ángel Arango de Bogotá, 3 de febrero de 2011 (2011/02)

[https://lecturasdeleclipse.files.wordpress.com] Web. 03/12/2019.

Vallejo 2013: Fernando Vallejo. Logoi. Una gramática del lenguaje literario. México: Fondo de Cultura Económica.

Villena Garrido 2005: Francisco Villena Garrido. «La sinceridad puede ser demoledora. Conversaciones con Fernando Vallejo». Ciberletras, 13. [http://www.lehman.cuny.edu/ciberletras/v13/villenagarrido. htm] Web 03/12/2019. 


\title{
THE PASSION FOR LANGUAGE IN LA RAMBLA PARALELA AND LA VIRGEN DE LOS SICARIOS
}

\begin{abstract}
Summary
One of the greatest passions of Fernando Vallejo (Medellín, Colombia, 1942), biologist, writer, filmmaker, fan of classical music, is the passion for language in its most diverse dimensions. He is fascinated by the language in its ceaseless movement and in its many forms, but criticizes the normative attitude of academic institutions and the use of language for political purposes. The objective of this study is to show the importance of the grammar in two novels by Vallejo, La Virgen de los sicarios and La Rambla paralela, and to analyze the use of language in the selected examples. In both novels the protagonist is a firstperson narrator called, as the author, Fernando. In the first, Fernando is an old homosexual grammarian who returns to his native Medellin after having lived many years outside the country, in the second the narrator is an old Colombian homosexual writer who arrives in Barcelona to give a conference at the Book Fair in the Catalan capital. In La Virgen de los sicarios, comments prevail over the jargon of the communes, in La Rambla paralela words from the dialect of Antioquia and Colombian Spanish are explained. The style in the analyzed novels stands out for its complexity, the superposition of registers of the spoken and the written languages, an abundant vocabulary, the use of metaphors and reiterations, the introduction of the most diverse subjects. Irony, sarcasm, black humor prevail as the sharp criticism of the situation in Colombia in particular and in the world in general, but also a deep melancholy, a lacerating nostalgia for the past and happy times of childhood.
\end{abstract}

Keywords: Fernando Vallejo, grammar, the jargon of the communes, antioqueńismos, colombianisms. 